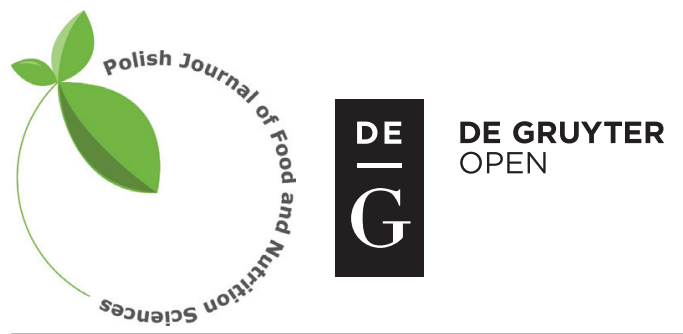

Pol. J. Food Nutr. Sci., 2017, Vol. 67, No. 4, pp. 293-299

DOI: $10.1515 /$ pjfns-2016-0033 http://journal.pan.olsztyn.pl

Original research article

Section: Food Chemistry

\title{
Selected Rheological Properties of RS3/4 Type Resistant Starch
}

\author{
Matgorzata Kapelko-Żeberska*, Tomasz Zięba, Radosław Spychaj, Artur Gryszkin \\ The Faculty of Food Science, Wroclaw University of Environmental and Life Science, \\ Chetmońskiego 37/41, 51-630 Wroclaw, Poland
}

Key words: retrograded potato starch, acetylated distarch adipate, rheological properties

This study was aimed at determining the effect of acetylation degree and crosslinking of retrograded starch with adipic acid on selected rheological properties of prepared pastes and gels. The esterification of retrograded starch allowed obtaining preparations with various degrees of substitution with residues of acetic $(0.7-11.2 \mathrm{~g} / 100 \mathrm{~g})$ and adipic acids $(0.1-0.3 \mathrm{~g} / 100 \mathrm{~g})$. Acetylation and crosslinking caused a decrease in amylose content of the preparations $(3-21 \mathrm{~g} / 100 \mathrm{~g})$. Solubility of the preparations in water, in a wide range of variability, was increasing along with an increasing degree of acetylation and with a decreasing degree of crosslinking $(19-100 \mathrm{~g} / 100 \mathrm{~g})$. Values of most of the rheological coefficients determined based on the flow curves of the prepared pastes and mechanical spectra of gels $\left(3.5<\mathrm{K}<31.5 \mathrm{~Pa} \times \mathrm{s}^{\mathrm{n}}, 4.2<\tau_{0 \mathrm{C}}<70 \mathrm{~Pa}, 0.26<\operatorname{tg} \alpha<0.57\right)$ were increasing in a wide range along with increasing crosslinking of starch. Changes in the rheological properties upon the effect of double modification were not the sum of changes proceeding as a result of single modifications. Instead, interaction of both factors was observed. The conducted modifications enable modelling the properties of produced preparations.

\section{INTRODUCTION}

Starch production in 2018 is estimated to reach as many as $133.5 \mathrm{mln}$ ton [Global Industry Analysts, 2015]. Industrially-produced starch is utilized only in a negligible part. Most of starch is processed using biochemical, physical and chemical methods. Modification of starch is aimed at imparting it specified physicochemical traits, respectively to the assumed mode of its potential application. One of the recent trends in its modification is the production of the so-called resistant starch which owing to reduced susceptibility to amylolysis serves a prebiotic function in a human body [Sajilata et al., 2006; Zaragoza et al, 2011]. Industrially, preparations of this type are produced from maize starch ("Hi-Maize" by Starch Australia Ltd.; "Hylon VII", "Novelose 240" by National Starch and Chemical Company; "Amylomaize VII" by Cerestar Inc.; and "CrystaLean" by Opta Food Integredients Inc.). These preparations are characterized by a significant resistance, but do not form viscous pastes [Leszczyński, 2004; Sajilata et al., 2006]. Recent studies have been focused on the production of resistant starch from potato starch through its processing into retrograded form and then its chemical modification [Haralampu, 2000; Yu et al., 2015]. Starches of these type are characterized by considerable resistance and undergo pasting, owing to which - apart from their basic prebiotic function - they may be potentially applied as

\footnotetext{
* Corresponding Author: Tel.: +48 7132054 87; Fax: +48 7132052 21;

E-mail: malgorzata.kapelko@wnoz.up.wroc.pl (M. Kapelko-Żeberska)
}

food additives to model the texture of food products [Song et al, 2011; Yu et al., 2015]. Acetylation of retrograded starch increases starch resistance to the action of amylases [Kapelko et al., 2012a], whereas its crosslinking with adipic acid increases viscosity of the prepared pastes, as demonstrated in a short communication by Zięba et al. [2014]. In our previous work, we analyzed how changes in the degree of substitution of acetylated adipate of retrograded starch (RS 3/4 type resistant starch) may affect - in a wide range - the resistance (up to $c a$. 70\%) and pasting characteristics of the modified preparations [Kapelko-Żeberska et al., 2015]. The objective of this study was, in turn, to determine the effect of the degree of acetylation and crosslinking with adipic acid of retrograded potato starch on its selected traits and on rheological properties of the prepared pastes and gels.

\section{MATERIALS AND METHODS}

\section{Materials}

The initial raw material was Superior Standard potato starch produced by PEPEES Łomża S. A. (Poland) in 2012. Starch was modified with acetic acid anhydride (analytically pure) and adipic acid (analytically pure) purchased at $\mathrm{POCH}$ SA Gliwice (Poland).

\section{Production of starch preparations}

Starch preparations were produced following the method described in our previous manuscript [Kapelko-Żeberska et al., 2015]. Starch retrogradation was accomplished through 
the freezing of a starch paste with the concentration of $10 \mathrm{~g} / 100 \mathrm{~g}$ at a temperature of $-20^{\circ} \mathrm{C}$ for 3 days, followed by its defrosting at a temperature of $20^{\circ} \mathrm{C}$ for 2 days. The precipitated starch was flushed with distilled water, dried at $30^{\circ} \mathrm{C}$ for $24 \mathrm{~h}$, ground, and sieved through a screen with 400 mesh size [Kapelko et al., 2012].

Afterwards, the retrograded starch was subjected to double chemical modification including its acetylation and crosslinking with adipic acid. The starch was acetylated with $3.25,6.5,13.0,26.0$ or $52.0 \mathrm{~mL}$ of acetic acid anhydride per $100 \mathrm{~g}$ of starch, accordingly to the methodology provided by Kapelko et al. [2012]. In turn, crosslinking was carried out with the use of a crosslinking agent prepared by hot-dissolving $20 \mathrm{~g}$ of adipic acid in $80 \mathrm{~g}$ of acetic anhydride. As in the case of acetylation, starch was modified with various doses of the crosslinking agent, i.e. $0.25,0.5,1,2$ or $4 \mathrm{~mL}$ of the crosslinking agent per $100 \mathrm{~g}$ of starch, according to the method described by Zięba et al. [2014]. The resultant preparations were several times flushed with distilled water, dried and ground - analogously to the procedure of retrograded starch preparation.

\section{Determination of the content of acetate groups}

Determination of acetate groups content was conducted according to the method of Wurzburg [1987] modified by Singh \& Nath [2012]. A weighted portion of starch (10 g) was transferred with distilled water $(65 \mathrm{~mL})$ to an Erlenmeyer flask. The suspension was neutralized against phenolphthalein with a $0.1 \mathrm{~mol} / \mathrm{L}$ solution of $\mathrm{NaOH}$. Afterwards, $25 \mathrm{~mL}$ of $0.5 \mathrm{~mol} / \mathrm{L} \mathrm{NaOH}$ were added and the sample was stirred for $35 \mathrm{~min}$. Next, the solution was titrated with a $0.5 \mathrm{~mol} / \mathrm{L}$ $\mathrm{HCl}$ solution. The degree of acetylation, expressing the number of grams of acetic acid residues in $100 \mathrm{~g}$ of the modified preparation, was computed from the formula:

$$
A=\frac{\left(P_{0}-P_{w}\right) \times N_{k} \times 0.043 \times 100}{M}[\mathrm{~g} / 100 \mathrm{~g}]
$$

where: $\mathrm{P}_{0}$ - volume $(\mathrm{mL})$ of $\mathrm{HCl}$ solution used to titrate $25 \mathrm{~mL}$ of $0.5 \mathrm{~mol} / \mathrm{L} \mathrm{NaOH}, \mathrm{P}_{\mathrm{w}}-$ volume $(\mathrm{mL})$ of $\mathrm{HCl}$ solution used to titrate the sample with acetylated starch, $\mathrm{N}_{\mathrm{k}}$ - acid titre, and $\mathrm{M}$ - content $(\mathrm{g})$ of starch dry matter in the sample.

\section{Determination of the content of adipic groups}

The content of adipic groups was determined according to the method developed by Zięba et al. [2014]. A weighted portion of the sample $(1 \mathrm{~g})$ was transferred with distilled water $(50 \mathrm{~mL})$ into an Erlenmeyer flask. Next, $1 \mathrm{~mL}$ of a water solution of glutaric acid and $50 \mathrm{~mL}$ of a $4 \mathrm{~mol} / \mathrm{L}$ $\mathrm{NaOH}$ solution were added under continuous stirring, and the mixture was stirred by another $5 \mathrm{~min}$. Afterwards, $20 \mathrm{~mL}$ of $12 \mathrm{~mol} / \mathrm{L} \mathrm{HCL}$ were added and the sample was cooled to $20^{\circ} \mathrm{C}$. The mixture was three-fold extracted with $100 \mathrm{~mL}$ of ethyl acetate. After each extraction, the supernatant was decanted to an Erlenmayer flask containing $20 \mathrm{~g}$ of anhydrous potassium sulfate, and the mixture was shaken for $10 \mathrm{~min}$ and filtrated. The solution was evaporated using a vacuum evaporator (pressure $50 \mathrm{mmHg}$, temperature $40^{\circ} \mathrm{C}$ ). Then, $2 \mathrm{~mL}$ of pyridine and $1 \mathrm{~mL}$ of Bis(trimethylsilyl)trifluoroacetamide (BSTFA) were added to dry residues for their complete solubilization. After $1 \mathrm{~h}$, the sample was subjected to the chromatographic analysis using a PYE UNICAM series 104 gas chromatograph with a flame ionization detector (FID), a glass column $(2.1 \mathrm{~m} \times 1.83 \mathrm{~mm}$ i.d.) packed with $5 \%$ OV-17 on Chromosorb G/AW-DMCS with the granulation of 100/120 mesh. Separation parameters were as follows: carrier gas - nitrogen; flow rate $-40 \mathrm{~mL} / \mathrm{min}$; detector temperature $-250^{\circ} \mathrm{C}$; injector temperature $-240^{\circ} \mathrm{C}$; column temperature $-140^{\circ} \mathrm{C}$; injection volume $-0.1 \mu \mathrm{L}$; and retention time -2.8 min for glutaric acid and 4.5 min for adipic acid.

The content of adipic acid in the sample was determined based on the standard curve plotted for the samples with a known content of the acid.

\section{Determination of amylose content with Morrison's method}

Amylose content was determined according to the method elaborated by Morrison \& Laignelet [1983]. A weighted portion of starch $(120 \mathrm{mg}$ ) was dissolved in $20 \mathrm{~mL}$ of the solution containing: 1 part of $4 \mathrm{~mol} / \mathrm{L}$ urea and 9 parts of dimethyl sulfoxide (DMSO). Then, $1 \mathrm{~mL}$ of the solution was collected from this sample, and $97 \mathrm{~mL}$ of distilled water and $2 \mathrm{~mL}$ of a iodine solution ( $2 \mathrm{~g}$ of potassium iodide and $0.2 \mathrm{~g}$ of sublimated iodine per $100 \mathrm{~mL}$ of the solution) were added. Absorbance of the solutions was measured $15 \mathrm{~min}$ after iodine solution addition, against a reference sample (not containing starch) using a CE 2010 spectrophotometer (Cecil Instruments, England) at a wavelength of $635 \mathrm{~nm}$.

\section{Determination of swelling power and water solubility at $8^{\circ} \mathrm{C}$}

Swelling power and solubility in water of the preparations were determined according to the method developed by Richter et al. [1986]. The preparation of acetylated and crosslinked retrograded starch was used to produce an aqueous suspension containing $1 \mathrm{~g}$ of starch per $100 \mathrm{~g}$ of the solution. The suspension was shaken for $30 \mathrm{~min}$ at $80^{\circ} \mathrm{C}$. Afterwards, it was cooled to $20^{\circ} \mathrm{C}$ and centrifuged for 30 min using a Biofuge 28RS centrifuge (Heraeus Sepatech, Germany) with acceleration to $22,500 \times g$. The separated supernatant was determined for dry matter content with the gravimetric method, and the precipitate remaining in the centrifuge tubes was weighed. Solubility indicates the amount of starch substance which after centrifugation is dissolved in the supernatant and is expressed in g/100 g. Swelling power determines the volume of water absorbed by the remaining part of starch and is expressed in $\mathrm{g} / \mathrm{g}$.

Starch solubility was computed according to the following formula:

$$
R=\frac{d m}{a} \times 100[\mathrm{~g} / 100 \mathrm{~g}]
$$

where: R - solubility (g/100 g), dm - dry matter of supernatant $(\mathrm{g} / 100 \mathrm{~g})$, and a - concentration of the suspension $(\mathrm{g} / 100 \mathrm{~g})$.

Swelling power of starch was computed according to the following formula: 


$$
W=\frac{m_{\text {prec }}-b \times((100-R) / 100)}{b \times(100-R)} \times 100[\mathrm{~g} / 100 \mathrm{~g}]
$$

where: $\mathrm{W}$ - swelling power (g water/g preparation), $\mathrm{m}_{\text {prec }}-$ mass of precipitate in a centrifuge test tube $(\mathrm{g}), \mathrm{b}$ - weighted portion of starch in a centrifuge test tube $(\mathrm{g})$, and $\mathrm{R}$ - solubility $(\mathrm{g} / 100 \mathrm{~g})$.

\section{Determination of flow curves of pastes using Haake oscillating-rotary viscometer}

Determination was conducted according to the method developed by Zięba et al. [2011]. Starch pastes with the concentration of $5 \mathrm{~g} / 100 \mathrm{~g}$ were prepared by stirring the starch suspension at $96^{\circ} \mathrm{C}$ for $30 \mathrm{~min}$. The flow curves of pastes were determined using an RS 6000 Rheostress oscillating-rotational viscosimeter (Haake, Germany). The analysis was carried out at a temperature of $50^{\circ} \mathrm{C}$ in the system of coaxial cylinders, at a shear rate of $1-300 \mathrm{~s}^{-1}$. The determined flow curves were described with the following equations:

$$
\begin{aligned}
& \text { Oswald de Waele: } \tau=K \times \dot{\gamma}^{n} \\
& \text { Casson: } \tau=\tau_{0 \mathrm{C}}^{0.5}+\left(\eta_{\mathrm{C}} \times \dot{\gamma}\right)^{0.5}
\end{aligned}
$$

where: $\tau$ - shear stress $(\mathrm{Pa}), \mathrm{K}$ - consistency coefficient $\left(\mathrm{Pa} \times \mathrm{s}^{\mathrm{n}}\right), \dot{\gamma}$ - shear rate $\left(\mathrm{s}^{-1}\right)$, and $\mathrm{n}-$ flow behavior index, $\tau_{0 \mathrm{C}}-$ yield stress $(\mathrm{Pa}), \eta_{\mathrm{C}}-$ Casson's plastic viscosity $(\mathrm{Pa} \times \mathrm{s})$.

\section{Determination of mechanical spectra using Haake oscillating-rotary viscometer}

Mechanical spectra of starch gels were determined based on the method developed by Zięba et al. [2011]. Starch pastes with the concentration of $5 \mathrm{~g} / 100 \mathrm{~g}$ were prepared analogously as in the case of flow curves determination, then cooled to a temperature of $25^{\circ} \mathrm{C}$ and kept at this temperature before measurement for $15 \mathrm{~min}$. Determination was conducted with an RS 6000 Rheostress rheometer (Haake, Germany) in the system of coaxial cylinders (type Z38AL) at a constant deformation amplitude of 0.03 , and a frequency range from 0.1 to $10 \mathrm{~Hz}$. The mechanical spectra obtained allowed determining the phase shift angle tangent ( $\left.\operatorname{tg} \alpha=G^{\prime} / G^{\prime}\right)$, being a quotient of loss modulus G" value and elasticity modulus G'value read out at the frequency of $1 \mathrm{~Hz}$.

\section{Statistical analysis}

In order to determine the effect of the conducted chemical modifications on the investigated properties, the results obtained were subjected to two-way analysis of variance at a significance level of $p<0.01$. Calculations were performed using Statistica ver. 10.0 software [StatSoft, Inc., 2011].

\section{RESULTS AND DISCUSSION}

The esterification of retrograded starch allowed obtaining preparations with degrees of substitution with residues of acetic from 0.7 to $11.2 \mathrm{~g} / 100 \mathrm{~g}$ and adipic acid in the range of $0.1-0.3 \mathrm{~g} / 100 \mathrm{~g}$.

The statistical analysis demonstrated that the applied factors and their interaction had a significant effect on the ana- lyzed properties of all preparations. A change in the value of parameters induced by the interaction of both factors (acetylation degree and crosslinking degree) was presented in the form of surface diagrams plotted following the procedure of weighted estimate with the least squares method (Figures 1-5). Graphical presentation of results is aimed at depicting the high variability of properties and possibility of their modification through changing the degree of acetylation and the degree of crosslinking.

Acetylation of potato starch causes changes in the structure of starch granules and in the degree of crystallinity [Muljana et al., 2010; Diop et al., 2011; Han et al., 2012]. Starch depolymerization is likely to proceed during this process, which causes changes in the mean molecular weight [Berski et al., 2011; Simsek et al., 2012]. Both acetylation with acetic acid anhydride and crosslinking with adipic acid contributed to a decrease in amylose content of the preparations from 21 to $3 \mathrm{~g} / 100 \mathrm{~g}$ (Figure 1). This decrease was greater along with the higher total degree of esterification. A similar tendency was observed in the case of acetylated retrograded starch [Kapelko et al., 2012a]. Many works are available on the effect of changes in amylose content on starch granules subjected to esterification, however their results are not explicit. According to studies of some authors, acetylated starch contains more amylose than the native starch does [Simsek et al., 2012; Singh et al., 2012], whereas other authors state the opposite [Kapelko et al., 2012; Emeje et al., 2012; Wani et al., 2012; Zięba et al., 2013]. In turn, works by Akintayo et al. [2009] and Huang et al. [2007] show no significant differences in contents of amylose and amylopectin. Considerably fewer literature data concern changes in amylose content of starch subjected to the crosslinking process. Jane et al. [1992] report that the crosslinking of native starch does not

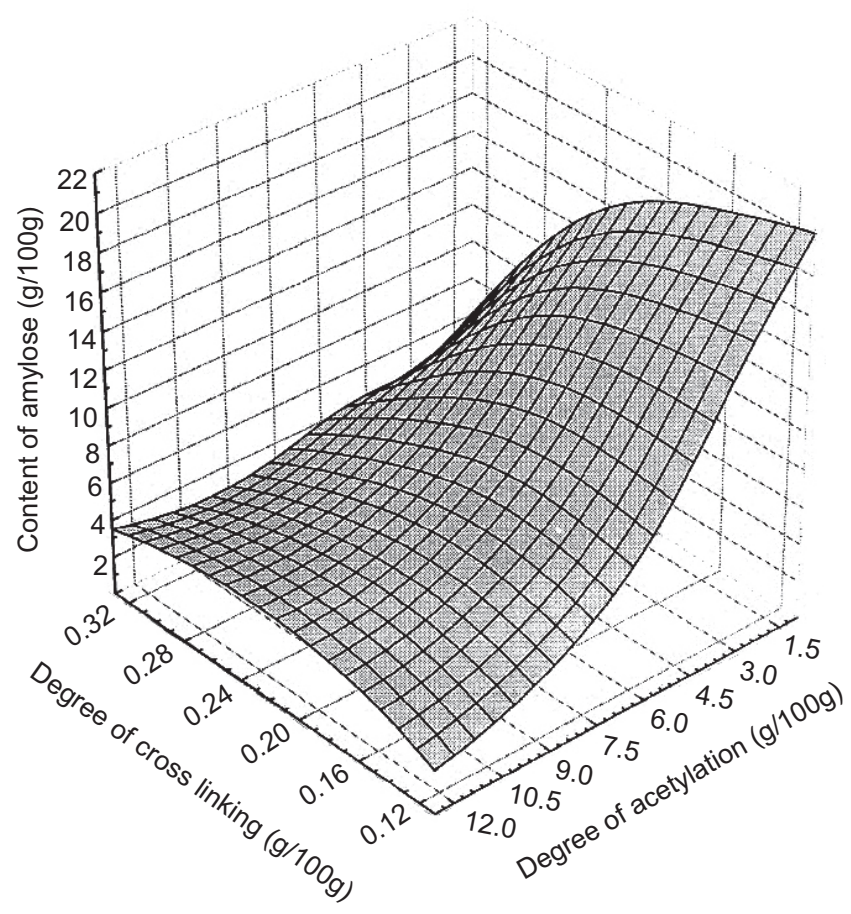

FIGURE. 1. Effect of an esterification degree of the produced acetylated adipate of retrograded starch on amylose content. 
induce changes in the molecular weight of amylose, which probably results from crosslinks formation only within amylopectin molecules. In turn, the crosslinking of pure amylose isolated from starch granules increases its molecular weight [Jane et al., 1992]. Apparently conflicting results of studies enable speculating that the changes occurring in amylose during chemical modifications are, to a great extent, dependent on reaction conditions.

The physical properties of esterified starch, particularly its behavior in water, are determined by, i.a., type of raw material and reagent applied, and process conditions including $\mathrm{pH}$, temperature, and duration [Huang et al., 2007; Ali, \& Has-
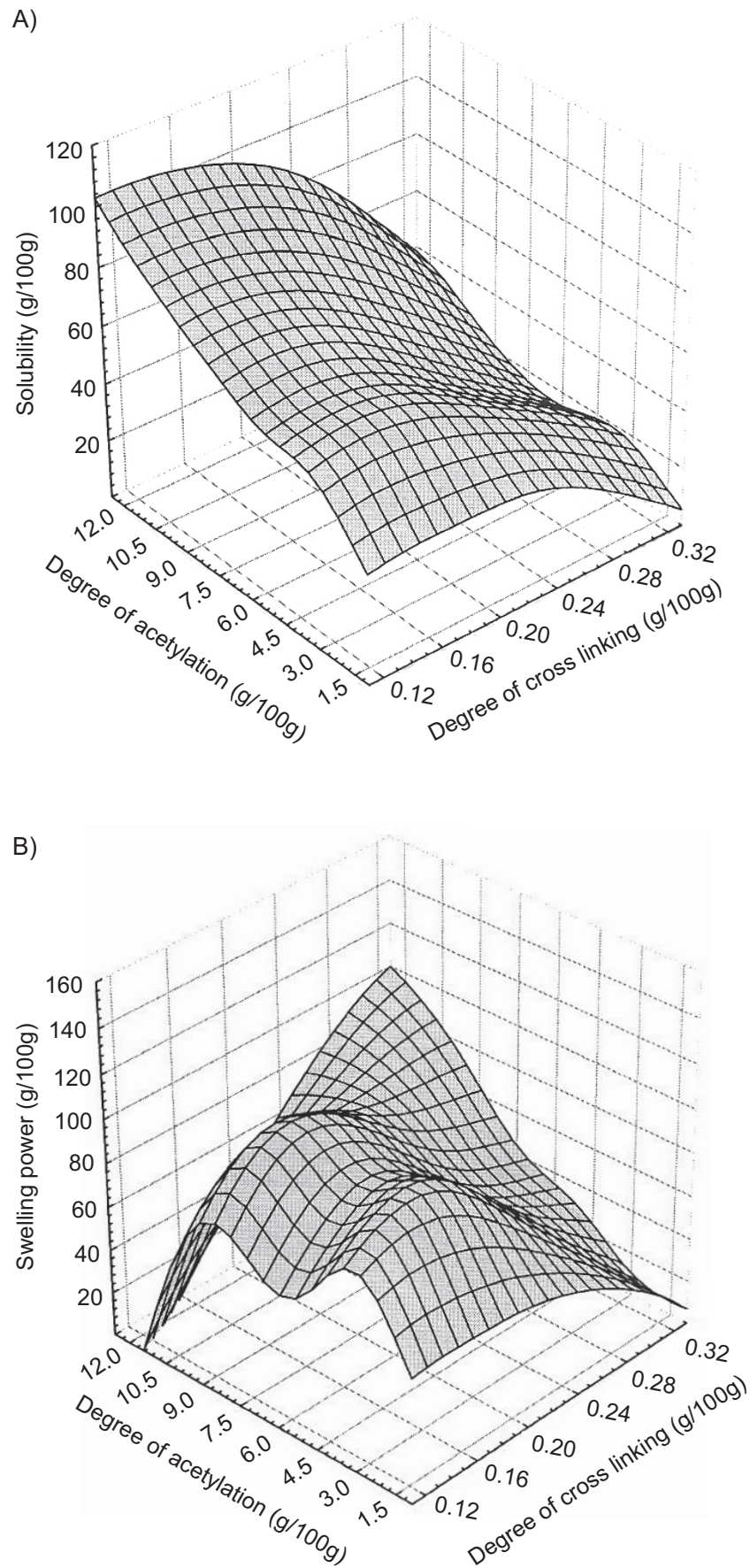

FIGURE. 2. Effect of an esterification degree of the produced acetylated adipate of retrograded starch on its solubility in water (A) and swelling power (B). nain, 2011; Bushra et al., 2013]. The monoesters with a low degree of substitution (the maximum percentage of substitution with acetic acid residues reaches $2.5 \%$; percentage of substitution with adipic acid residues reaches $0.135 \%$ ) applied in the food industry are usually characterized by increasing solubility and swelling power along with an increasing esterification degree. A successive increase in the degree of substitution leads to a decrease in the values of these parameters [Kapelko et al., 2012a; Wang, \& Copeland, 2012]. Solubility of the produced preparations in water ranged from 19 to $100 \mathrm{~g} / 100 \mathrm{~g}$ (Figure 2a). It was increasing in a wide variability range along with an increasing degree of acetylation and decreasing crosslinking with adipic acid residues. In turn, the swelling power of the preparations ranged from 0.7 to $100 \mathrm{~g} / \mathrm{g}$ (Figure 2b). The high variability of swelling power values is probably due to the coupling of two modification procedures that have different effects on this characteristic.

One of the basic analyses applied to determine rheological properties of starch pastes involves determination of their flow curves. Rheological coefficients that describe the beginning of shearing at the determined flow curves include: yield stress $\tau_{0 \mathrm{C}}$ and consistency coefficient $\mathrm{K}$. The $\tau_{0 \mathrm{C}}$ is a measure of stress needed to induce shearing, whereas the consistency coefficient $\mathrm{K}$ indicates paste viscosity at the beginning of this process. The influence of the degree of acetylation and degree of crosslinking of starch on both these coefficients had a similar course (Figure 3 and Figure 4a). The viscosity of paste at the beginning of shearing was increasing significantly at low degrees of substitution of one of the chemical modifications applied. At a low acetylation degree, both $\tau_{0 \mathrm{C}}$ and $\mathrm{K}$ were increasing in a wide variability range along with an increasing degree of crosslinking. A similar tendency was observed at the low degree of crosslinking with adipic acid residues and at the increasing acetylation degree. At the intermediate values

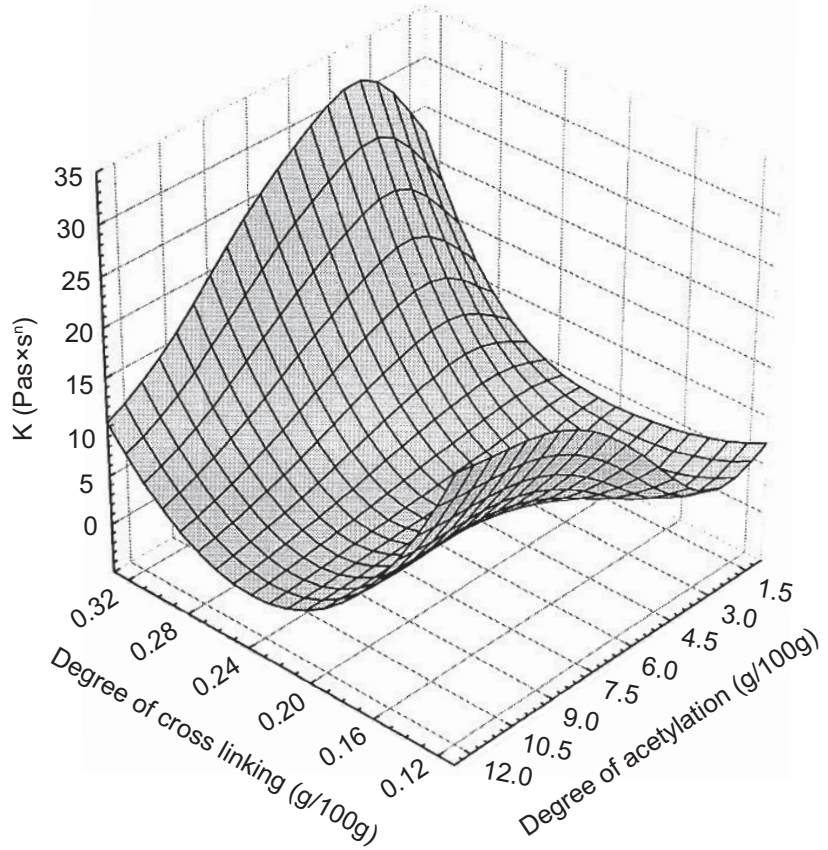

FIGURE. 3. Effect of an esterification degree of the produced acetylated adipate of retrograded starch on the value of consistency coefficient (K). 

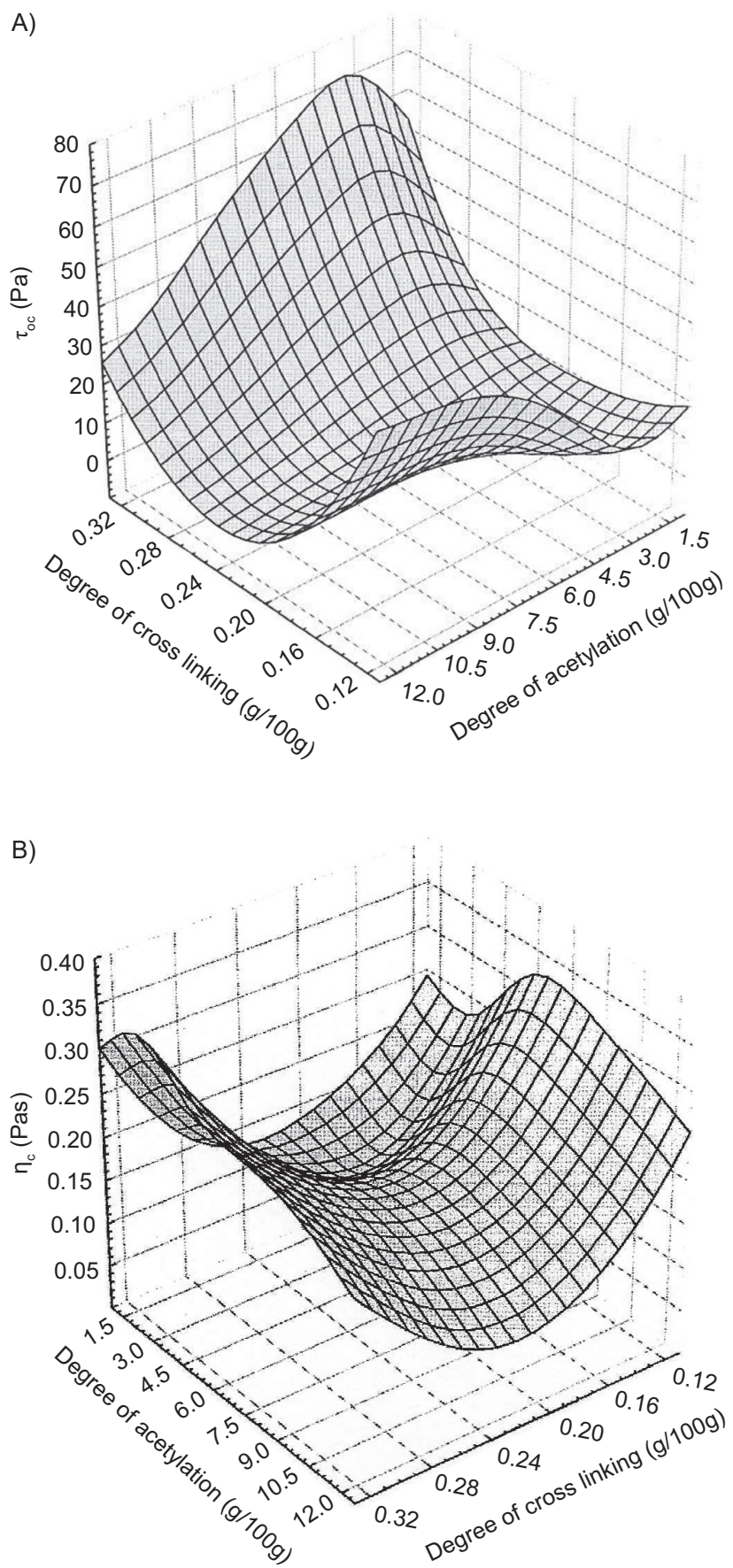

FIGURE. 4. Effect of an esterification degree of the produced acetylated adipate of retrograded starch on yield stress $\tau_{\mathrm{oc}}$ (A) and plastic viscosity $\eta_{\mathrm{c}}(\mathrm{B})$.

of esterification with acetic and adipic acids, the discussed coefficients reached relatively low values. Changes in the values of coefficients $\tau_{0 \mathrm{C}}$ and $\mathrm{K}$ proceeding upon the influence of single modifications (acetylation or crosslinking with adipic acid) of retrograded starch were presented in previous works [Zięba et al., 2011; Kapelko et al., 2012a, 2015]. Changes in the discussed rheological coefficients along with a changing degree of acetylation are described by second order equations possessing maxima [Kapelko et al., 2012a]. In turn, the value of the consistency coefficient $\mathrm{K}$ of the paste prepared from retrograded starch adipate decreases along with a lower degree of starch crosslinking [Kapelko et al., 2015]. It may,

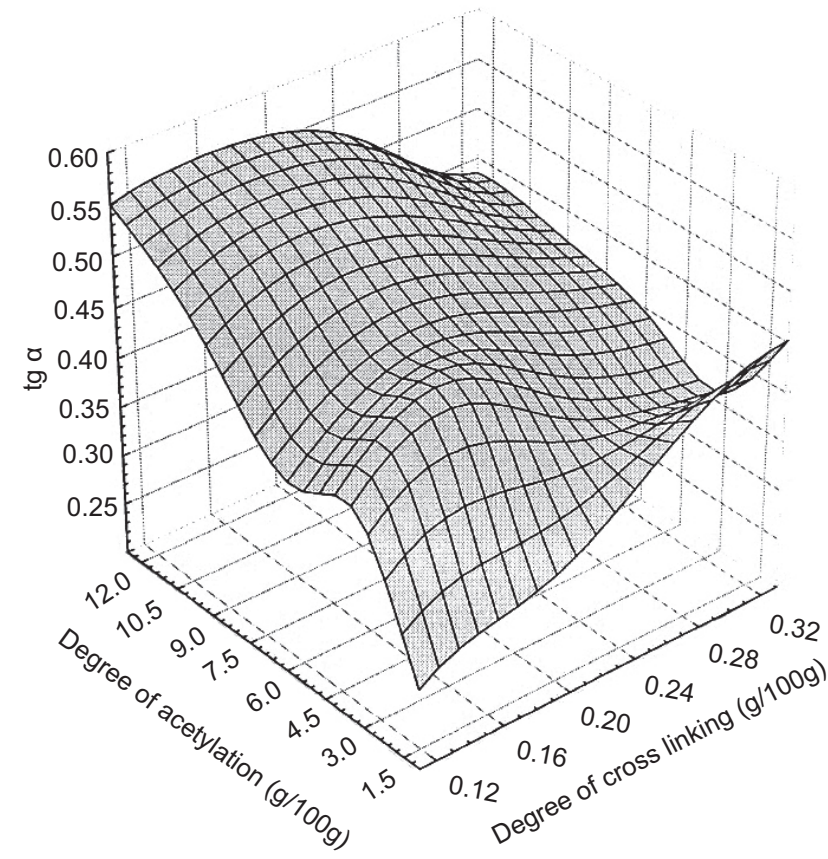

FIGURE. 5. Effect of an esterification degree of the produced acetylated adipate of retrograded starch on the tangent of phase angle shift $(\operatorname{tg} \alpha)$.

therefore, be concluded that the changes induced by double chemical modification were not the sum of changes proceeding as a result of single modifications. Instead, interaction of both factors was observed.

A measure of paste viscosity at the end of the shearing process is the $\eta_{C}$ coefficient determined from the Casson's equation. Changes upon the influence of crosslinking, in a wide range of variability, had a parabolic character with the minimal value, whereas changes induced by acetylation had a parabolic character and possessed the maximum value (Figure $4 b$ ). For this reason, the highest values of $\eta_{C}$ coefficient were achieved at the highest and the lowest crosslinking with adipic acid residues and the medium degree of acetylation. Analogous character of changes of $\eta_{C}$ coefficient was observed in the case of acetylated retrograde starch [Kapelko et al., 2012a].

Figure 5 depicts changes in $\operatorname{tg} \alpha$ being a measure of the strength of the formed gels. The tangent $\alpha$ expresses the relative contribution of viscous and elastic traits in modeling the viscoelastic properties of the material. The values tg $\alpha>0.1$ are typical of weak gels, whereas the values tg $\alpha<0.1$ characterize strong gels [Schramm, 1994]. All gels produced from preparations of acetylated adipate of retrograded starch formed weak gels $(0.26<\operatorname{tg} \alpha<0.57)$, and changes evoked by one modification were significantly determined by the esterification degree of the second modification. At low values of acetylation degrees, the increasing crosslinking was inducing an increase in $\operatorname{tg} \alpha$ value. An opposite tendency occurred at high substitution with acetic acid residues. At the low crosslinking of starch, the $\operatorname{tg} \alpha$ value was increasing in a wide variability range along with an increasing acetylation degree. This correlation was, however, not observed at higher starch crosslinking with adipic 
acid residues. As in the case of earlier discussed rheological coefficients, here we may also speak of the interaction of both modifying factors. The use of single chemical modifications of retrograded starch enable explicit determination of the character of changes in $\operatorname{tg} \alpha$ coefficient upon the influence of a varying degree of esterification. Its value decreases along with increasing crosslinking of retrograded starch adipate [Kapelko et al., 2015], and in the case of acetylated retrograded starch the changes have a character of the polynomial second degree function possessing the minimal value [Kapelko et al., 2012a].

\section{CONCLUSIONS}

The conducted esterification of retrograded starch allowed obtaining preparations with a various degree of substitution with acetic and adipic acids, which determined their properties. The total increase in esterification degree caused a decrease in amylose content. In a wide range of variability, the solubility of the analyzed preparations in water was increasing along with an increasing degree of acetylation and a decreasing degree of crosslinking with adipic acid residues. Viscosity of the formed pastes was increasing, in a wide range, along with increasing crosslinking of starch. The conducted modifications afford the possibility of modelling both the solubility and viscosity of pastes produced from acetylated adipate of retrograded starch.

\section{RESEARCH FUNDING}

Publication supported by Wroclaw Centre of Biotechnology, programme The Leading National Research Centre (KNOW) for years 2014-2018.

\section{CONFLICT OF INTEREST}

Authors declare no conflict of interest.

\section{REFERENCES}

1. Akintayo C.O., Akintayo E.T., Preparation, composition and physico-chemical characteristics of native, oxidized and acetylated African yambean (Sphenostylis Sternocarpa) starches. Adv. in Nat. Appl. Sci., 2009, 3, 196-203.

2. Ali T.M., Hasnain A., Functional and morphological characterization of low-substituted acetylated white sorghum (Sorghum bicolor) starch. Int. J. Polym. Anal. Ch., 2011, 16, 187-198.

3. Berski W., Ptaszek A., Ptaszek P., Ziobro R., Kowalski G., Grzesik M., Achremowicz B., Pasting and rheological properties of oat starch and its derivatives. Carbohydr. Polym., 2011, 83, 665-671.

4. Bushra M., Xu X.X., Pan S.Y., Microwave assisted acetylation of mung bean starch and the catalytic activity of potassium carbonate in free solvent reaction. Starch/Stärke, 2013, 65, 236-243.

5. Diop C.I.K., Li H.L., Xie B.J., Shi J., Combinatorial effects of mechanical activation and chemical stimulation on the microwave assisted acetylation of corn (Zea mays) starch. Starch/ Stärke, 2011, 63, 96-105.

6. Emeje M., Kalita R., Isimi C., Buragohain A., Kunle O., Ofoefule S., Synthesis, physicochemical characterization, and functional properties of an esterified starch from an underutilized source in Nigeria. Afr. J. Food Agric. Nutr. Dev., 2012, 12, 7001-7018.

7. Global Industry Analysts, INC. 2015. Starch: A Global Strategic Business Report - Highlights.

8. Han F., Liu M., Gong H., Lü S., Ni B., Zhang B., Synthesis, characterization and functional properties of low substituted acetylated corn starch. Int. J. Biol. Macromol., 2012, 50, 1026-1034.

9. Haralampu S.G., Resistant starch - a review of the physical properties and biological impact of RS3. Carbohydr. Polym., 2000, 41, 3, 285-292.

10. Huang J., Schols H.A., Jin Z., Sulmann E., Voragen A.G.J., Characterization of differently sized granule fractions of yellow pea, cowpea and chickpea starches after modification with acetic anhydride and vinyl acetate. Carbohydr. Polym., 2007, 67, 11-20.

11. Jane J., Xu A., Radosavljevic M., Seib P.A., Location of amylose in normal starch granules. I. Susceptibility of amylose and amylopectin to cross-linking reagents. Cereal Chem., 1992, 69, 4, 405-409.

12. Kapelko M., Zięba T., Golachowski A., Gryszkin A., Effect of the production method on the properties of RS3/RS4 type resistant starch. Part 1. Properties of retrograded starch (RS3) produced under various conditions and its susceptibility to acetylation. Food Chem., 2012, 135, 1494-1504.

13. Kapelko M., Zięba T., Michalski A., Effect of the production method on the properties of RS3/RS4 type resistant starch. Part 2. Effect of a degree of substitution on the selected properties of acetylated retrograded starch. Food Chem., 2012a, 135, 2035-2042.

14. Kapelko M., Zięba T., Michalski A., Gryszkin A., Effect of crosslinking degree on selected properties of retrograded starch adipate. Food Chem., 2015, 167, 124-130.

15. Kapelko-Żeberska M., Zięba T., Spychaj R., Gryszkin A., Acetylated adipate of retrograded starch as RS 3/4 type resistant starch. Food Chem., 2015, 188, 365-369

16. Leszczyński W., Resistant starch - classification, structure, production. Pol. J. Food Nutr. Sci., 2004, 13/54, 37-50.

17. Morrison W.R., Laignelet B., An improved colorimetric procedure for determining apparent and total amylose in cereal and other starches. J. Cereal Sci., 1983, 1, 9-20.

18. Muljana H., Picchioni F., Heeres H.J, Janssen L.P.B.M., Green starch conversions: Studies on starch acetylation in densified $\mathrm{CO}_{2}$. Carbohydr. Polym., 2010, 82, 653-662.

19. Richter M., Augustat S., Schierbaum F., Ausgewählte Methoden der Stärkechemie. 1968, VEB Fachbuch Verlag Leipzig.

20. Sajilata M.G., Singhal R.S., Kulkarni P.R., Resistant starch A review. Compreh. Rev. Food Sci. Food Safety, 2006, 5, 1-17.

21. Schramm G., Aspects of rheometry. 1994, in: A Practical Approach to Rheology and Rheometry. $2^{\text {nd }}$ Edition (ed. G. Schramm). Gebrueder HAAKE GmbH, pp. 15-35.

22. Simsek S., Ovando-Martínez M., Whitney K., Bello-Pérez L., Effect of acetylation, oxidation and annealing on physicochemical properties of bean starch. Food Chem., 2012, 134, 1796-1803.

23. Singh A.V., Nath N.K., Synthesis, characterization, and compatibility study of acetylated starch with lamivudine. J. Therm. Anal. Calorim., 2012, 108, 307-313.

24. Singh H., Sodhi N.S., Singh N., Structure and functional properties of acetylated sorghum starch. Int. J. Food Prop., 2012, 15, $312-325$ 
25. Song J.Y., Park J.H., Shin M., The effects of annealing and acid hydrolysis on resistant starch level and the properties of crosslinked RS4 rice starch. Starch/Stärke, 2011, 63, 147-153.

26. Wang S., Copeland L., New insights into loss of swelling power and pasting profiles of acid hydrolyzed starch granules. Starch/ Stärke, 2012, 64, 538-544.

27. Wani I.A., Sogi D.S., Gill B.S., Physicochemical properties of acetylated starches from some Indian kidney bean (Phaseolus vulgaris L.) cultivars. Int. J. Food Sci. Technol., 2012, 47, 1993-1999.

28. Wurzburg O.B., Modified Starches - Properties and Uses. 1987, Boca Raton Florida CRS Press Inc.

29. Yu S.X., Mu T.H., Zhang M., Ma M.M., Zhao Z.K., Effects of retrogradation and further acetylation on the digestibility and physicochemical properties of purple sweet potato flour and starch. Starch/Stärke, 2015, 67, 892 - 902.
30. Zaragoza E.F., Zapata E.S., Sendra E., Sayas E., Navarro C., Fernández-López J., Pérez-Alvarez J.A., Resistant starch as prebiotic: A review. Starch/Stärke, 2011, 63, 406-415.

31. Zięba T., Juszczak L., Gryszkin A., Properties of retrograded and acetylated starch preparations. Part 2. Dynamics of saccharification with amyloglucosidase and rheological properties of resulting pastes and gels. LWT - Food Sci. Technol., 2011, 44, 1321-1327.

32. Zięba T., Kapelko M., Szumny A., Effect of preparation method on the properties of potato starch acetates with an equal degree of substitution. Carbohydr. Polym, 2013, 94, 193-198.

33. Zięba T., Gryszkin A., Kapelko M., Selected properties of acetylated adipate of retrograded starch. Carbohydr. Polym., 2014, 99, 687-691.

Submitted: 31 December 2015. Revised: 27 July and 8 August 2016. Accepted: 21 September 2016. Published on-line: 19 January 2017. 
